\title{
Separate and joint scaling of perceived odor intensity of $n$-butanol and hydrogen sulfide
}

\author{
B. BERGLUND \\ University of Stockholm, Stockholm, Sweden \\ U. BERGLUND \\ Department of Environmental Design \\ Royal Institute of Technology, Stockholm, Sweden \\ and \\ T. LINDVALL \\ Department of Environmental Hygiene \\ Karolinska Institute, Stockholm, Sweden
}

\begin{abstract}
To determine which combination of scaling method and experimental procedure is optimal for measuring perceived odor intensity, the intensity perception of one odorous substance was scaled both separately and together with a second odorous substance in the same session. The methods used were magnitude estimation with and without a standard reference and cross-modal matching with finger span. The results show that separate and joint scalings of $n$-butanol and $\mathrm{H}_{2} \mathrm{~S}$ give identical scales, regardless of scaling method. Different results are obtained in magnitude estimations with a homoquality, a heteroquality, and no standard. From these results, one would not expect to find a single true power function independent of method. Cross-modal matching with finger span may be the best choice for odor intensity scaling, since it results in the widest response range, thereby giving the best resolution.
\end{abstract}

S. S. Stevens proposed a power function, $\mathbf{R}=$ $\mathrm{cS}^{n}$, to describe the relationship between perceived strength (R) and physical intensity (S) for prothetic continua. The magnitude of the exponent ( $\mathrm{n}$ ) is intended to reflect the transducing capacity of the sense organ, and is thus specific for the sense modality (S. S. Stevens, 1960). For most sensory continua, the exponent is less than one (e.g., brightness, loudness, odor intensity); for others, it is greater than one (e.g., force of handgrip, unpleasantness of electric shock). However, considerable variation in the values of the exponent for any given sense modality is reported (e.g., Engen \& Levy, 1955; S. S. Stevens, 1956). A steeper slope of the psychophysical function is sometimes obtained for the lower part of the stimulus continuum. To compensate for this deviation from a power function in its simplest form, a constant value $\left(S_{o}\right)$ was subtracted from the physical scale

The investigation was supported by grants from the Swedish Council for Social Science Research and the Swedish Environment Protection Board. We gratefully acknowledge the valuable assistance provided by Torsten Rehn, Sune Pettersson, and Per-Olof Olson. Requests for reprints should be sent to: Dr. B. Berglund, Department of Psychology, University of Stockholm, Box 6706, S-113 85 Stockholm, Sweden. values (Ekman, 1958; S. S. Stevens, 1959). Commonly reported causes of variations in exponents, as well as deviations from the power function, are individual differences among observers, sensory adaptation, masking, different stimulus parameters such as stimulus composition or range, and scaling method (for brief reviews, see, e.g., Marks, 1974; B. Berglund, Note 1).

For perceived odor intensity, the exponent of the power function varies considerably. The largest variations derive from the very nature of the odorous substance scaled and from the group of participants (Berglund, Berglund, Ekman, \& Engen, 1971). For example, the exponent for 2-phenyl ethyl alcohol is reported to be as low as 0.06 , while for eugenol it may reach 0.72 . Different devices for stimulus presentation produce variation in exponents: sniffing odors in a stream of air leads to a steeper psychophysical function than does sniffing from bottles (Cain, 1969). Furthermore, self- and cross-adaptation give steeper functions (Cain \& Engen, 1969). Puzzling variations in the exponent (from 0.22 to 0.45 ) have been found for hydrogen sulfide despite the enforced constancy of stimulus range, olfactometer, purity grade, and scaling method (Berglund, Berglund, \& Lindvall, 1973; Lindvall, 1974). 
Research into the effects of scaling method on the psychophysical function has shown that magnitude production results in higher exponents than various versions of magnitude estimation. This is true for several modalities (e.g., Hellman \&Zwislocki, 1963; S. S. Stevens \& Greenbaum, 1966). It is common knowledge that the use of a standard stimulus in magnitude estimation tends to raise the exponent of the power function. This is true for sensory continua such as loudness (Hellman \& Zwislocki, 1961, 1963; J. C. Stevens \& Tulving, 1957) and heaviness (S. S. Stevens \& Galanter, 1957) as well as for such nonsensory continua as perceived size of circles (MacMillan, Moschetto, Bialostozky, \& Engel, 1974). Some researchers report that, for sensory continua, a standard high in the stimulus range raises the exponent (e.g., Beck \& Shaw, 1961, 1965). For nonsensory continua such as perceived circle area, no such effect was found (MacMillan et al., 1974).

For perceived odor intensity, a comparison of scaling methods has been performed by Engen and Lindström (1963): Contrary to Beck and Shaw's results on loudness, they found that a standard placed in the middle of the stimulus range produced the steepest slope, but that the slope decreased as the standard approached either extreme. Cain and Engen (1969) later demonstrated that magnitude estimates of perceived odor intensity gave a higher exponent when no standard was introduced into the experiments.

In order to be able to use direct scaling methods in applied contexts, it is desirable to determine which combination of scaling method and experimental procedure is optimal for reducing the impact of irrelevant factors that affect odor intensity measures. The present experiments investigated the intensity perception of one odorous substance scaled alone and scaled together with a second odorous substance. The perceived odor intensity was scaled by three different methods: magnitude estimation, with and without a standard reference, and cross-modal matching using finger span. To elucidate effects of adaptation and context, the magnitude estimation method with a standard was employed with both a homoquality and a heteroquality standard.

\section{METHOD}

\section{Equipment}

An olfactometer as described by Lindvall (1970, pp. 23-26) was used. It consists essentially of a ventilated, air-conditioned test chamber in which are installed two odor-exposure hoods. Stable exposure concentrations are produced within the olfactometer by a well-defined dynamic flow of gas. Rapid changes in concentration are made possible by a capillary diluting system. The exposure equipment allows the subjects to breathe fairly naturally.

The subjects are exposed to the odor stimuli by inhaling through the hoods. Odor-free air (100 liter $/ \mathrm{min})$ flows through the hoods, and varying amounts of an odorous substance can be added to the air flow by means of the dosing system. This consists of cannulae of varying bores which can be driven electromagnetically in and out of the air stream.

\section{Stimuli}

The odorous substances used were $n$-butanol (p.a. Merck) and hydrogen sulfide (c.p. Matheson). A constant stream of nitrogen was passed through a glass tube of $n$-butanol at a constant temperature. Hydrogen sulfide was kept in tubes and was also prediluted with nitrogen.

Seven concentrations of each odorous substance were produced using seven calibrated capillaries selected to give geometric dilution series. The flows through the capillaries were repeatedly checked during the experiment and found to vary $5 \%$ at most. The gas flowing through the hoods was kept at about $21^{\circ} \mathrm{C}$ and $45 \%$ relative humidity, as was the air in the test chamber.

Since the odorant concentrations in the hoods cannot be analyzed due to the relative insensitivity of chemical methods available for short-term measurements, samples of the odorants were collected immediately in front of the capillaries at least twice during each experimental session. A gas chromatograph was used to determine the concentration of $n$-butanol (Aerograph 204B, flame-ionization detector). This instrument was repeatedly calibrated during each experimental session by use of standard samples of $n$-butanol $(5,000 \mathrm{ppm})$ in Mylar plastic bags. The concentration of hydrogen sulfide was determined by the gel technique described by Boström and Brosset (1969).

The concentrations of the two odorous substances were chosen to cover the range from the absolute threshold value (determined in a pilot experiment using the same equipment) to the maximum allowable concentration (MAC-value) established for occupational health purposes. The mean concentrations used as stimuli were $98,32,11,3.6,1.1,0.34$, and $0.11 \mathrm{ppm}$ for $n$-butanol and 11, $2.5,0.59,0.14,0.034,0.0088$, and $0.0021 \mathrm{ppm}$ for $\mathrm{H}_{2} \mathrm{~S}$. These values are the arithmetic means of the concentrations calculated from the precapillary chemical analyses and the capillary flows during the experiment. The coefficients of variation for the precapillary stimulus concentrations were $15 \%$ for $n$-butanol and $12 \%$ for hydrogen sulfide.

\section{Subjects}

Thirty-two subjects, 11 men and 21 women, participated in the experiments. The median age was 23 years. Almost all subjects were university students. The subjects were divided into four groups of 8 subjects each. The experiments involved different scaling instructions; no group of subjects participated in experiments involving more than one of these.

\section{Scaling Methods}

Three different scaling methods were used. In the magnitude estimation with a standard, the standard was fixed as the perceived odor intensity of 100 . The subjects were instructed to estimate the ratio (as a percentage) between the perceived intensity of the standard and the perceived intensity of the variable stimulus. In the magnitude estimation without a standard, the subjects were instructed to match numbers to the perceived odor intensity of the variable stimuli. In the cross-modal matching with finger span, a two-step scaling procedure was used (cf. Ekman, Berglund, Berglund, \& Lindvall, 1967). First, the subject matched his finger span (thumb to index finger) to the perceived odor intensity of the stimuli. Second, the finger-span continuum was scaled by magnitude production. The subjects gave their maximum finger spans before each experimental session. The subjects were instructed to begin each match from the zero position. They were only allowed to perceive their finger settings tactually.

Particular efforts were made to instruct the subjects to estimate perceived odor intensity and disregard possible differences in odor qualities which he might perceive during the different experimental sessions. 


\section{Experimental Procedure}

Each of the four groups of subjects (Group 1-4) participated in three different experiments (Experiments 1-3). Each experiment was performed using all the scaling methods. For each group, only one of the scaling methods was used for the three experiments, as shown in Table 1.

The three experiments were:

Experiment 1: Separate odor intensity scaling of seven concentrations of $\mathrm{H}_{2} \mathrm{~S}$. For the method of magnitude estimation with a standard, the strongest of the $\mathrm{H}_{2} \mathrm{~S}$ concentrations was used as the standard (homoquality standard).

Experiment 2: Separate odor intensity scaling of seven concentrations of $n$-butanol. For the method of magnitude estimation with a standard, the strongest of the $n$-butanol concentrations was used as the standard (homoquality standard).

Experiment 3: Joint scaling of the odor intensity of seven concentrations of $\mathrm{H}_{2} \mathrm{~S}$ and seven concentrations of $n$-butanol. For the method of magnitude estimation with a standard, the strongest concentration of either $n$-butanol (Group 2) or $\mathrm{H}_{2} \mathrm{~S}$ (Group 1) served as the standard (homoquality standard for one substance, heteroquality standard for the other).

For all groups, the investigation was divided into three successive parts. The first part consisted of the separate scaling of the two substances (Experiments 1 and 2), i.e., a complete scale for one substance was obtained before the scaling of the other substance was performed (balanced order). In the second part, both substances were scaled jointly in an irregular order (Experiment 3), i.e., both substances at all concentrations were presented. The third part was identical to the first part. In each experiment, each subject made four estimates of each stimulus concentration. The stimulus concentrations were always presented to the subjects in irregular order.

The subjects participated in six 25-min experimental sessions. A recess of at least 25 min was observed between sessions, and no subject participated in more than three sessions in 1 day. One session included seven concentrations, each presented four times, and thus covered the whole of Experiment 1 or Experiment 2 but only half of Experiment 3, respectively. The stimulus exposures lasted $3 \mathrm{sec}$, and the interstimulus intervals were $30 \mathrm{sec}$. In the magnitude estimations, the standard stimulus exposure preceded the variable stimulus by $3 \mathrm{sec}$.

\section{RESULTS AND DISCUSSION}

\section{Data Treatment}

Group scales of perceived odor intensity were calculated as geometric means for each experiment and method. The finger-span values representing the per- ceived odor intensities were transformed into numerical values for each subject by his psychophysical function for finger span. These functions were of the same form as obtained in earlier scaling experiments (cf. Berglund, Berglund, \& Lindvall, 1971; Ekman et al., 1967).

\section{Concordance and Consistency Data}

Two groups of subjects (Groups 1 and 2) scaled odor intensity by the same method (method of magnitude estimation with a standard, cf. Table 1). The concordance of results (Pearson's product-moment correlation) between the two groups with respect to scales for $\mathrm{H}_{2} \mathrm{~S}$ (Experiment 1) was 0.96 , and for $n$-butanol (Experiment 2) 0.99 during the first part of the study. During the third part, the coefficients were 0.99 for both substances. This agreement between the groups makes reasonable the pooling of these data into mean scales of perceived odor intensity, which are then based on 128 observations. The high agreement between Groups 1 and 2 with respect to the results of Experiments 1 and 2 also allows a comparison between the two groups with respect to the use of different standards in magnitude estimation (homoquality or heteroquality standard, Experiment 3).

The consistency of the data (first part compared with the identical third part) obtained by the different methods is illustrated in Table 2 in terms of mutual regression analyses (Indow, Note 2). The consistency is high for all methods (or groups of subjects) and substances. Therefore, the data in Parts 1 and 3 were pooled. This procedure leaves us with mean scales of perceived odor intensity in Experiments 1 and 2 based on 64 observations (except for magnitude estimation with a standard, which is based on 128 observations). In Experiment 3 (second part), the mean scales are always based on 32 observations because it was never repeated as in Experiments 1 and 2 (see Table 1).

Table 1

Schematic Presentation of the Experimental Design

\begin{tabular}{|c|c|c|c|c|}
\hline Method & $\begin{array}{l}\text { Group of } \\
\text { Subjects }\end{array}$ & First Part* & Second Part & Third Part* \\
\hline Magnitude estimation with standard & 1 & $\begin{array}{l}\text { Experiment } 1 \\
\text { Experiment } 2\end{array}$ & Experiment $3 * *$ & $\begin{array}{l}\text { Experiment } 1 \\
\text { Experiment } 2\end{array}$ \\
\hline Magnitude estimation with standard & 2 & $\begin{array}{l}\text { Experiment } 1 \\
\text { Experiment } 2\end{array}$ & Experiment $3 \dagger$ & $\begin{array}{l}\text { Experiment } 1 \\
\text { Experiment } 2\end{array}$ \\
\hline Magnitude estimation no standard & 3 & $\begin{array}{l}\text { Experiment } 1 \\
\text { Experiment } 2\end{array}$ & Experiment 3 & $\begin{array}{l}\text { Experiment } 1 \\
\text { Experiment } 2\end{array}$ \\
\hline Cross-modal matching with finger span & 4 & $\begin{array}{l}\text { Experiment } 1 \\
\text { Experiment } 2\end{array}$ & Experiment 3 & $\begin{array}{l}\text { Experiment } 1 \\
\text { Experiment } 2\end{array}$ \\
\hline
\end{tabular}


Table 2

Comparison of Response Data Obtained During the First and Third Parts of the Investigation (Experiments 1 and 2)

\begin{tabular}{|c|c|c|c|c|}
\hline Method & Substance & $\begin{array}{c}\text { Substance } \\
\mathrm{a} \\
\end{array}$ & $\begin{array}{c}\text { Slope } \\
\mathrm{b}\end{array}$ & $\begin{array}{c}\text { Correlation* } \\
\mathrm{r}\end{array}$ \\
\hline $\begin{array}{l}\text { Magnitude estimation with standard } \\
\text { (Groups } 1 \text { and } 2 \text { ) }\end{array}$ & $\begin{array}{l}\mathrm{H}_{2} \mathrm{~S} \\
\text { n-butanol }\end{array}$ & $\begin{array}{l}-.43 \\
-.07\end{array}$ & $\begin{array}{l}1.17 \\
1.29\end{array}$ & $\begin{array}{l}.99 \\
.99\end{array}$ \\
\hline Magnitude estimation, no standard & $\begin{array}{l}\mathrm{H}_{2} \mathrm{~S} \\
\text { n-butanol }\end{array}$ & $\begin{array}{l}-.49 \\
-.78\end{array}$ & $\begin{array}{r}1.04 \\
.89\end{array}$ & $\begin{array}{l}.99 \\
.99\end{array}$ \\
\hline Cross-modal matching with finger span & $\begin{array}{l}\mathrm{H}_{2} \mathrm{~S} \\
\text { n-butanol }\end{array}$ & $\begin{array}{l}-4.51 \\
-1.58\end{array}$ & $\begin{array}{r}1.17 \\
.89\end{array}$ & $\begin{array}{l}.98 \\
.98\end{array}$ \\
\hline
\end{tabular}

$*_{n}=7$

\section{Separate and Joint Scaling}

The investigation was designed to study the role of the scaling context. The context was varied by the separate (Experiments 1 and 2) and joint scaling (Experiment 3) of two odorous substances.

The perceived odor intensity scales for $\mathrm{H}_{2} \mathrm{~S}$ and $n$-butanol are presented in Figure 1, where the scales obtained separately are plotted against those obtained jointly. Separate and joint scalings are seen to produce identical scales regardless of method. The methods investigated under these conditions were magnitude estimation with a homoquality standard, magnitude estimation with no standard, and crossmodal matching with finger span. We can conclude that scaling $\mathrm{H}_{2} \mathrm{~S}$ and $n$-butanol jointly does not affect either of the two scales of perceived odor intensity, at least when the response ranges are approximately the same.

\section{Scaling With or Without a Standard Reference}

The scaling context was also varied via the scaling method itself: that is, by the use of a homoquality standard, a heteroquality standard, or no standard at all in magnitude estimation, and the use of crossmodal matching. The effects of method on the odor intensity scales are shown in Figures 2 and 3. Both figures represent results obtained under joint scaling conditions (Experiment 3).

From Figure 2, it is evident that, for the method of magnitude estimation, a heteroquality standard gives an approximately linear relation in $\log -\log$ coordinates to the scales obtained by magnitude estimation without a standard, as well as to the scales obtained by cross-modal matching. In the diagrams, the data points fall systematically off the diagonal in such a way that the various methods would give psychophysical power functions having different multiplicative constants and in some cases also different exponents. In magnitude estimation, a heteroquality standard and no standard at all differ in result only with regard to the multiplicative constant of the functions (Figure 2 left diagram). One explanation for the results presented in Figure 2 may be that the metric properties of the scales are similar only when scales refer to the same response continuum (e.g., numbers); in other words, a subject may have different conceptions of ratios for different response continua (the continuum manipulated by the subject).

In contrast to the overall agreement between the various scales found in Figure 2, the use of a homo-

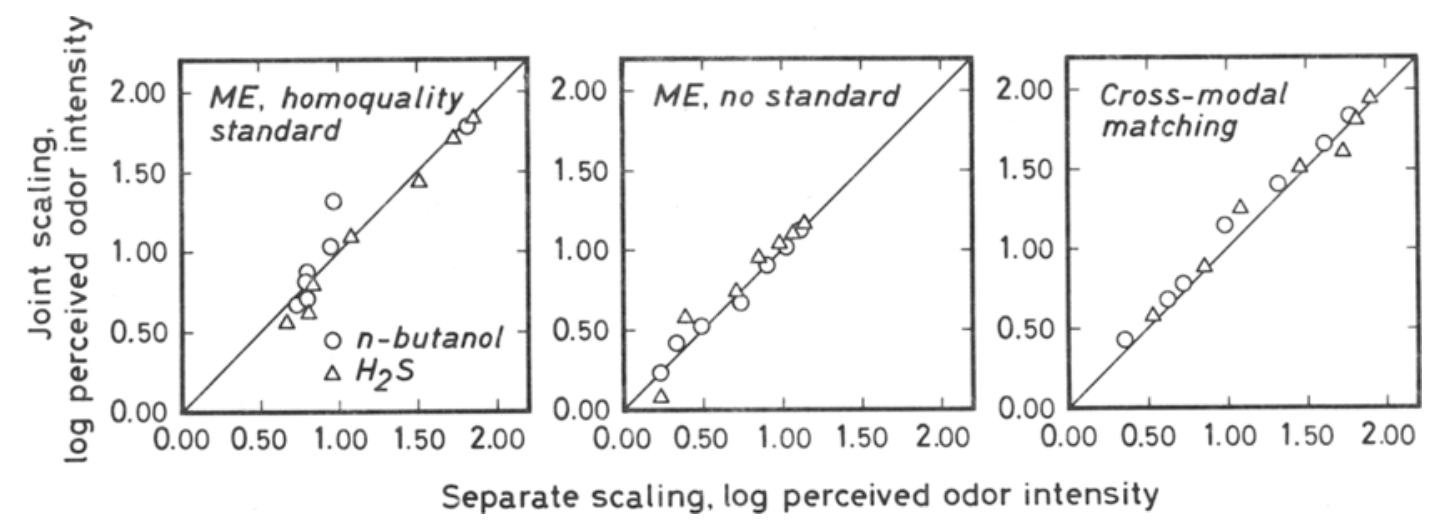

Figure 1. Comparison of separate and joint scaling of the perceived odor intensity of $\mathrm{H}_{2} \mathrm{~S}$ and $n$-butanol with three methods. 

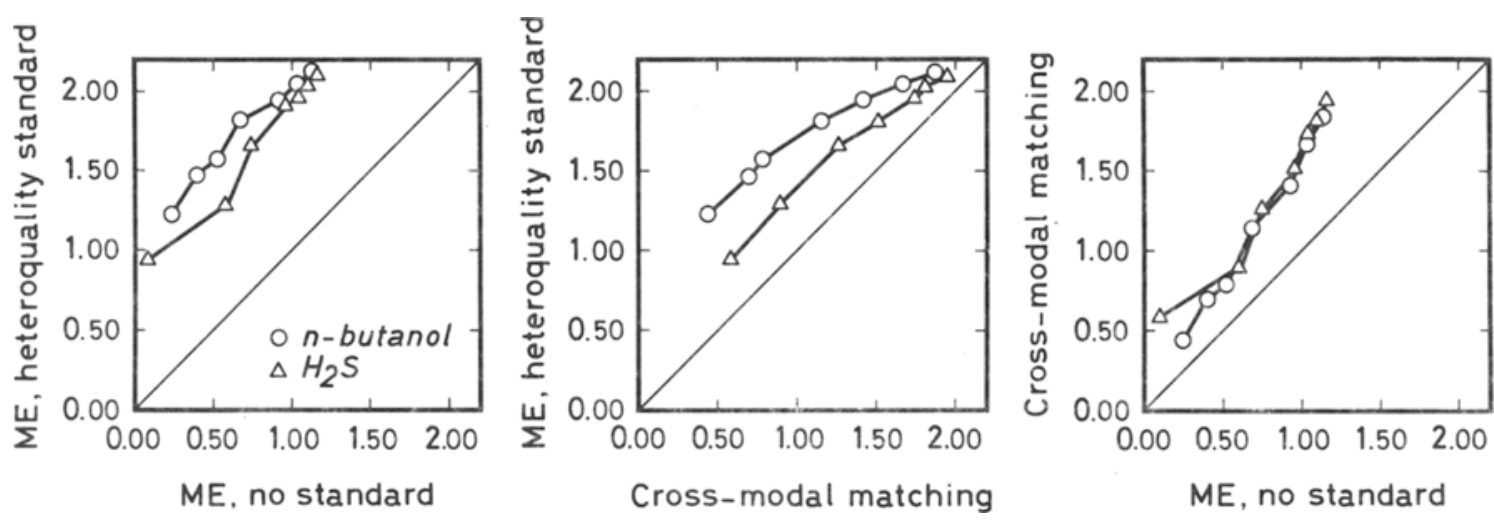

Figure 2. Joint scaling conditions: Comparison of the perceived odor intensity of $\mathrm{H}_{2} \mathrm{~S}$ and $n$-butanol obtained by different scaling methods, including magnitude estimation with a heteroquality standard.

quality standard in magnitude estimation results in scales consistently different from the scales obtained by the other methods, Figure 3 . The homoquality standard gives scales that are curvilinearly related to the scales from the other methods when viewed in $\log -\log$ plots.

The use of a homoquality standard in magnitude estimation apparently elicits a low response differentiation in the lower part of the response range. Several explanations for this outcome are possible. First, it may reflect a simple systematic error due to averaging when several estimates for a weak concentration are zero and a few higher estimates will determine the average. Therefore, the present data were also calculated as arithmetic means both with the zero estimates included and with them not included. All the calculations result in scales with a low differentiation of values for the weak concentrations.

A second explanation may stem from a judgmental bias. In an experiment where the modulus is set beforehand by the experimenter (or the subject), the subject may hesitate to use the numbers of the scale that are far from the modulus. Since only the results for magnitude estimation with a homoquality standard are deviating, the judgmental bias due to number behavior can be excluded (also, the response range is slightly larger for magnitude estimation with a standard than without).

It is obvious that the choice of a standard of weak instead of strong concentration might have presented us a more favorable outcome also for magnitude estimation with a standard. However, from a practical point of view, a weak concentration is more difficult to control, especially under field conditions. Furthermore, scaling research by Svenson (Note 3) has clearly shown that a standard in the middle of the range is accompanied by judgmental errors due to subjects' tendency to treat multiples and fractions differently so that two scales emerge, one for fractions and another for multiples.

The most likely explanation is that a homoquality standard causes the sense of smell to undergo adaptation (cf. Cain \& Engen, 1969), the adaptive effects being more pronounced in the lower response ranges.
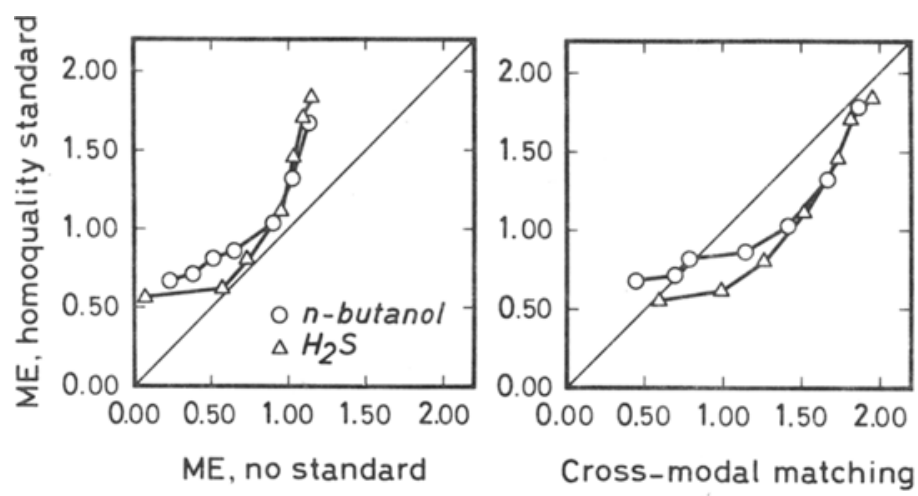

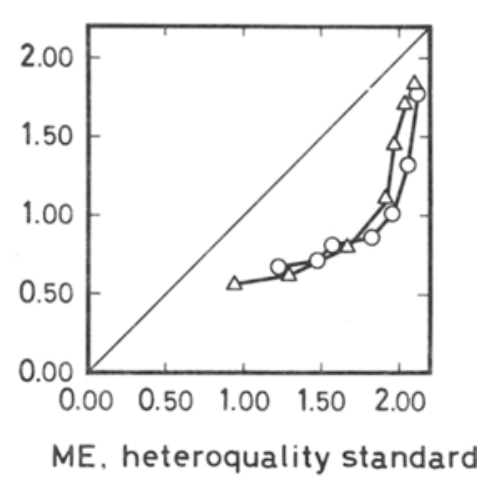

Figure 3. Joint sealing conditions: Comparison of the perceived odor intensity of $H_{2} S$ and $n$-butanol obtained by different scaling methods, including magnitude estimation with a homoquality standard. 

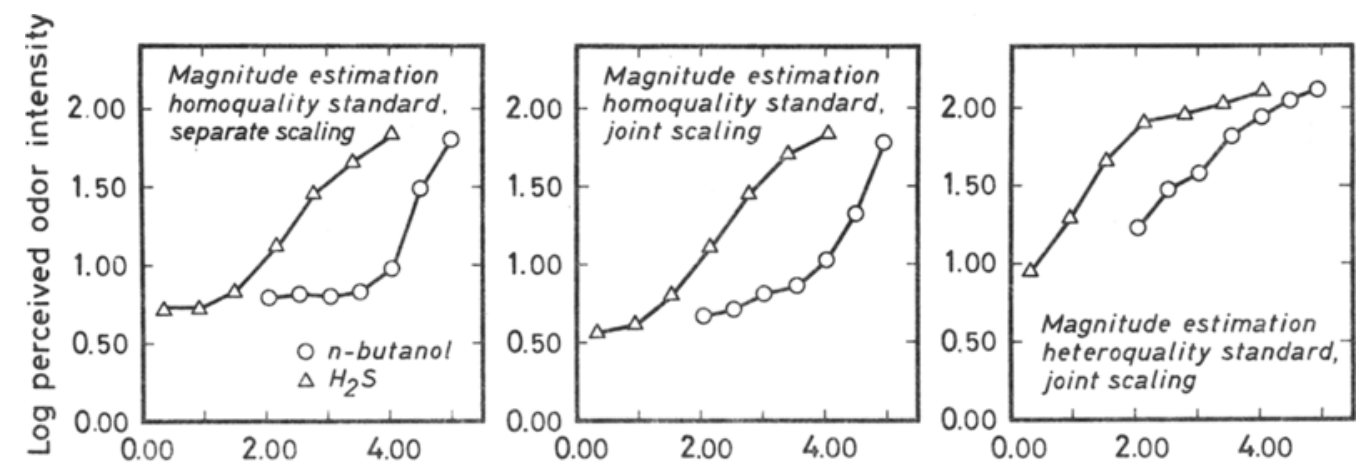

Log stimulus concentration in ppb

Figure 4. Psychophysical functions for $\mathrm{H}_{2} \mathrm{~S}$ and $n$-butanol obtained by magnitude estimations with homoquality and heteroquality standards under separate and joint scaling conditions.

These results agree with those reported by $U$. Berglund (1974): Sensory adaptation seems to distort the power function by a relative increase of the lower perceptual scale values. The undistorted part of the function seems to increase in slope with an increase in adaptation.

\section{Psychophysical Functions for $\mathrm{H}_{2} \mathrm{~S}$ and $n$-Butanol}

From the results presented thus far, one would not expect to find a single true power function unaffected by method. The power functions fitted to the data obtained by separate as well as joint scaling for magnitude estimation with a standard are presented in Figure 4. It is quite clear that a homoquality standard for intensity scaling (Figure 4, two diagrams to the left) diminishes the response range for weaker stimuli, the effect being more pronounced in the separate scaling condition. A heteroquality standard also seems to distort the power function for hydrogen sulfide, though not as much for $n$-butanol. It is not clear whether this distortion derives from the method or substance and technical procedure.

Figure 5 presents the psychophysical functions for $n$-butanol and $\mathrm{H}_{2} \mathrm{~S}$ obtained using the two methods
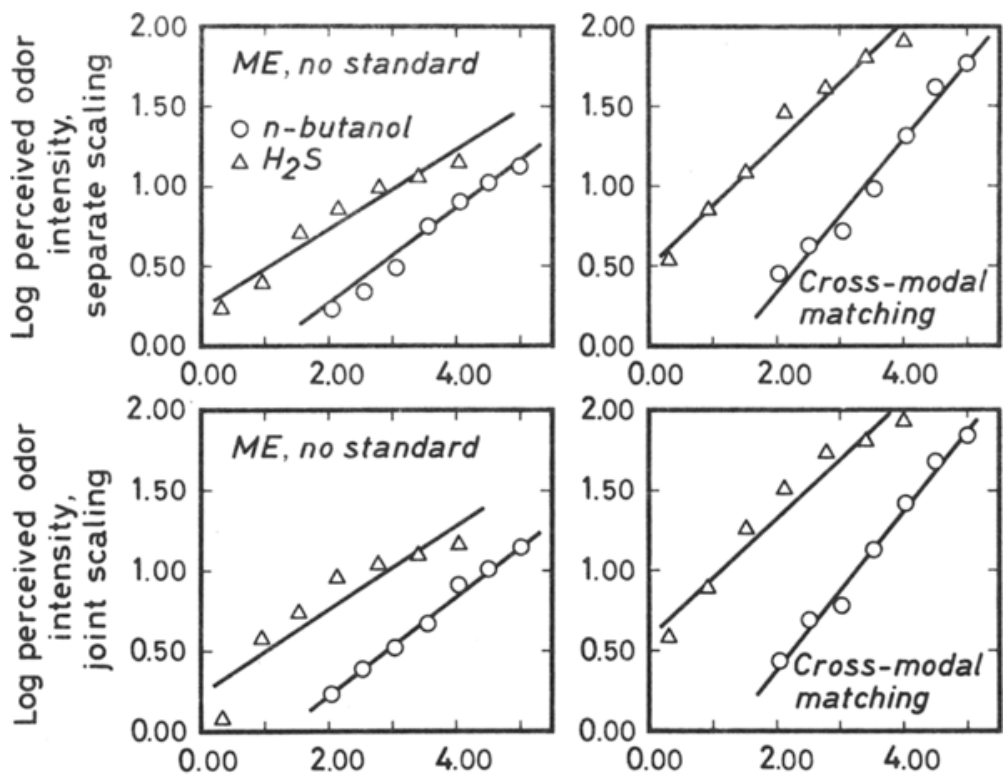

Log stimulus concentration in ppb

Figure 5. Psychophysical functions for $\mathrm{H}_{2} \mathrm{~S}$ and $n$-butanol obtained by magnitude estimations without a standard and cross-modal matching under separate and joint scaling conditions. 
Table 3

Parameters of Power Functions for $\mathrm{H}_{2} \mathrm{~S}$ and n-Butanol

\begin{tabular}{|c|c|c|c|c|c|c|c|}
\hline \multirow[b]{2}{*}{ Method } & & \multicolumn{3}{|c|}{ n-butanol } & \multicolumn{3}{|c|}{$\mathrm{H}_{2} \mathrm{~S}$} \\
\hline & & a & $\mathrm{b}$ & $r$ & $\underline{\mathbf{a}}$ & $\mathrm{b}$ & $\mathbf{I}$ \\
\hline Magnitude estimation, no standard & $\begin{array}{l}\text { Separate scaling } \\
\text { Joint scaling }\end{array}$ & $\begin{array}{l}-.45 \\
-.42\end{array}$ & $\begin{array}{l}.32 \\
.32\end{array}$ & $\begin{array}{l}.99 \\
.99\end{array}$ & $\begin{array}{l}.23 \\
.24\end{array}$ & $\begin{array}{l}.25 \\
.26\end{array}$ & $\begin{array}{l}.97 \\
.92\end{array}$ \\
\hline Cross-modal matching with finger span & $\begin{array}{l}\text { Separate scaling } \\
\text { Joint scaling }\end{array}$ & $\begin{array}{l}-.61 \\
-.60\end{array}$ & $\begin{array}{l}.48 \\
.49\end{array}$ & $\begin{array}{l}.99 \\
.99\end{array}$ & $\begin{array}{l}.50 \\
.59\end{array}$ & $\begin{array}{l}.38 \\
.37\end{array}$ & $\begin{array}{l}.98 \\
.97\end{array}$ \\
\hline
\end{tabular}

Note-a stands for intercept and $b$ stands for exponent.

without a standard, for both separate and joint scaling. The linearity in the log-log plots confirms that the psychophysical relationships are power functions. The parameters of the functions differ between methods but not between separate and joint scaling conditions.

It is noteworthy that Moskowitz, Dravnieks, Cain, and Turk (1974) reported $n$-butanol to have an exponent of .66 and an absolute threshold of ca. 2 to $5 \mathrm{ppm}$, the latter roughly corresponding to the breaking point of the function for $n$-butanol in Figure 4 (left diagram). The size of their exponents also happens to coincide with the slope of the psychophysical relationship above the breaking point. This coincidence may depend on adaptation effects (Cain \& Engen, 1969), caused in our case by the homoquality standard stimulus, and in the case of Moskowitz et al. (1974) by noise in their equipment or the like. Our experiments, using the same scaling method as that used by Moskowitz et al. (1974), have shown that when the equipment allows for a wider stimulus range, the exponent for $n$-butanol becomes lower (cf. Figure 5, upper two diagrams). Therefore, their psychophysical function for $n$-butanol is not, as they suggested, suitable for standardization in odor research. The basic requirement for standard odor functions is that they must be valid for a wide enough stimulus range; the practical requirements are that the scaling method and equipment be standardized.

A presentation of the power functions obtained by the method of magnitude estimation without a standard and by the finger-span technique is given in terms of intercepts, $a$, and exponents, $b$, in Table 3. The method of magnitude estimation without a standard gives lower exponents and lower intercepts than does the finger-span method. The relation between the parameters of the power functions obtained by the two methods is not a simple one: for example, for the joint scaling condition, the ratio between exponents for the two substances is not constant between methods, being 1.32 for finger-span and 1.23 for magnitude estimation. The highest resolution in perceptual response is obtained using the finger-span technique; this method may, in fact, be a better choice than magnitude estimation for scaling odor intensity.

\section{REFERENCE NOTES}

1. Berglund, B. An analysis of some basic mechanisms of sensory perception with direct scaling methods. Reports from the Psychological Laboratories, University of Stockholm, 1971, Suppl. 6.

2. Indow, T. A computer program to fit a straight line when both variables are subject to error. Report PPR-317 from the Psychophysics Laboratory, Harvard University, Cambridge, Mass., 1956.

3. Svenson, O. On direct judgment in psychophysics. Reports from the Psychological Laboratories, University of Stockholm, 1971, Suppl. 4.

\section{REFERENCES}

Beck. J., \& Shaw, W. A. The scaling of pitch by the method of magnitude estimation. American Journal of Psychology, 1961, 74, 242-251.

BECK, J., \& SHAW, W. A. Magnitude of the standard, numerical value of the standard, and stimulus spacing in the estimation of loudness. Perceptual and Motor Skills, 1965, 21, 151-156.

Berglund, B., Berglund, U., Ekman, G., \& Engen, T. Individual psychophysical functions for 28 odorants. Perception \& Psychophysics. 1971, 9, 379-384.

Berlund, B., Berglund, U., \& Lindvall, T. On the principle of odor interaction. Acta Psychologica, 1971, 35, 255-268.

Berglund, B., Berglund, U., \& Lindvall, T. Perceptual interaction of odors from a pulp mill. In Proceedings of the 3rd International Clean Air Congress, October. 1973. Duisseldorf: VDI-Verlag, 1973.

Berglund, U. Dynamic properties of the olfactory system. Annals of the New York Acadmy of Sciences, 1974, 237, 17-27.

Boström, C. E., \& Brosset, G. A method for simultaneous determination of hydrogen sulfide and sulfur dioxide in flue gases. Atmospheric Environment, 1969, 3, 407-416.

CAIN, W. S. Odor intensity: Differences in the exponent of the psychophysical function. Perception \& Psychophysics, 1969, 6. 349-354.

CAIN. W. S., \& ENGEN, T. Olfactory adaptation and the scaling of odot intensity. In C. Pfaffman (Ed.), Olfaction and taste III. New York: Rockefeller University Press, 1969.

Ekman, G. Two generalized scaling methods. Journal of Psychology, 1958, 45, 287-295.

Ekman, G., Berglund, B., Berglund, U., \& Lindvall, T. Perceived intensity of odor as a function of time of adaptation. Scandinavian Joumal of Psychology, 1967, 8, 177-186.

ENGEN, T., \& LEVY, N. The influence of standards on psychophysical judgment. Perceptual \& Motor Skills, 1955, 5, 193-197.

ENGEN, T, \& Lindström, C. O. Psychophysical scales of the odor intensity of amyl acetate. Scandinavian Journal of Psychology, 196.3, 4. 23-28.

Heliman, R. P., \& Zwislock, J. Some factors affecting the estimation of loudness. Journal of the Acoustical Society of America, 1961, 33, 687-694. 
Hellman. R. P.. \& Zwislocku, J. Monaural loudness function at $1000 \mathrm{cps}$ and interaural summation. Joumal of the Acoustical Society of America, 1963, 35, 856-865.

Lindvall, $\mathrm{T}$. On sensory evaluation of odorous air pollutant intensities. Nordisk Hygienisk Tidskrift, 1970, Suppl. 2.

Lindvall, T. Monitoring odorous air pollution in the field with human observers. Annals of the New York Academy of Sciences, $1974,237,247-260$.

MacMillan, N. A., Moschetro, C. F., Bialostozky, F. M., \& ENGEL, L. Size judgment: The presence of a standard increases the exponent of the power law. Perception \& Psychophysics, 1974, 16, 340-346.

MARKs, L. E. Sensory processes. The new psychophysics. New York: Academic Press, 1974.

Moskowitz, H., Dravnieks, A., Cain, W. S., \& Turk, A. Standardized procedure for expressing odor intensity. Chemical Senses and Flavor, 1974, 1, 235-237.

Stevens, J. C., \& Tulving, E. Estimation of loudness by a group of untrained observers. American Journal of Psychology, 1957. 70, 600-605.

STEVENS, S. S. The direct estimation of sensory magnitudesloudness. American Journal of Psychology, 1956, 69, 1-25.

Stevens, S. S. Tactile vibration: Dynamics of sensory intensity. Journal of Experimental Psychology, 1959, 57, 210-218.

Stevens, S. S. The psychophysics of sensory function. American Scientist, 1960, 48, 226-253.

Stevens, S. S., \& Galanter, E. H. Ratio scales and category scales for a dozen perceptual continua. Journal of Experimental Psychology, 1957, 54, 377-411.

Stevens, S. S., \& Greenbaum, H. B. Regression effect in psychophysical judgment. Perception \& Psychophysics, 1966. 1. 439-446.

(Received for publication September 14, 1977; revision accepted January 9,1978 .) 